\title{
O Cinema e a Percepção Sensível
}

\author{
Tiago Penna*
}

Resumo

Para Benjamin, uma das funções sociais do cinema é a de oferecer um equilíbrio entre o homem e o aparelho. O novo ambiente social das grandes cidades modernas, crucialmente afetado pelas técnicas, modificara os costumes e a sensibilidade humana. No entanto, esta mesma implementação técnica pode prover aos espectadores do cinema uma forma terapêutica contra possíveis distúrbios psíquicos, ao mesmo tempo que nos oferece um exercício para nossa percepção do mundo social que nos cerca; de sorte que o cinema exerce um papel terapêutico e didático em seus espectadores.

Palavras-chave: Cinema - Técnicas - Percepção.

Abstract

For Benjamin the cinema has, among other functions, the social purpose of offering a balance between man and machine. The new social environment of the great modern cities, which has been crucially affected by techniques, has modified customs and human sensitivity. However, this technical implementation can provide the viewers a therapy against possible mental disorders. At the same time, the technique modifies our perception of the social world that surrounds us. This way, the cinema has a therapeutic and didactic role in its viewers.

Key-words: Cinema - Techniques - Perception.

\section{O Cinema e a percepção sensível}

Walter Benjamin, ao analisar a estética cinematográfica - em seu célebre ensaio $A$ Obra de Arte na Era de Sua Reprodutibilidade Técnica (1935) -, propõe, através de um prognóstico, conceitos revolucionários, que em suas palavras significa que não poderiam ser abarcados pelo fascismo, mas, por outro lado, tinham como intuito colaborar para uma reconstrução da história e para uma práxis política revolucionária que buscassem implementar a revolução socialista. Benjamin diagnostica uma relação - tanto epistemológica quanto

* Bacharel e Mestre em Filosofia pela UFPB, Professor Assistente pela UFAL terapêutica - entre o cinema e a percepção sensível do homem moderno. E destaca tal relacionamento como um dos aspectos revolucionários mais cruciais desta nova forma de arte fundada pelo advento das técnicas de reprodução.

O cinema, devido à sua própria essência (audiovisual), permite uma ampliação da percepção sensível, que irá revelar aspectos da realidade até então desconhecidos para o 
homem. Por isso, esse desvelamento permite também um aumento do conhecimento humano. Além disso, devido à constituição do cinema se embasar no avanço das técnicas, o cinema irá funcionar como um exercício terapêutico para a população se acostumar e melhor apreender as modificações de seu próprio meio social cotidiano, também afetado pelos avanços das tecnologias. Mirian Bratu Hansen (1999) diz que o esforço benjaminiano foi o de conceber o impacto que o ambiente alterado industrialmente tem sobre a sensibilidade humana, e sobre a reestruturação da subjetividade e da coletividade na época moderna; questionando, desta forma, a crise da estética, e as condições das possibilidades de memória e de experiência intersubjetivas diante das formas de arte pós-auráticas. Assim, a modificação estética ocasionada pelos avanços tecnológicos permite uma alteração epistemológica e uma avaliação política da sociedade moderna.

A imagem cinematográfica (assim como a fotográfica), pode ser considerada como constituinte da memória voluntária ${ }^{1}$, e, assim, pode permitir um acesso genuíno ao passado oprimido através do presente cristalizado, auxiliando na possibilidade de confecção de uma imagem dialética, na qual irá permitir ao espectador figurar um futuro revolucionário e redimido. Desta forma, o cinema admite também que a subjetividade de seus "leitores" (seus espectadores), alimente-se de imagens que podem porventura se "reauratizar", revelando o presente revolucionário de mudança futura, como aquele presente cristalizado que fulgura em um momento iminente de perigo.

Poderíamos questionar que tipo de filme permitiria essa "reauratização", e, embora Benjamin não tenha se referido especificamente a nenhum tipo de filme neste sentido, podemos especular que ele estaria pensando nos filmes histórico-políticos russos, em especial os de Sergei Eisenstein, e nos filmes surrealistas (como "O Cão Andaluz”, de Salvador Dali e Luiz Buñuel), como obras de arte politizadas com viés revolucionário. O novo ambiente social das grandes cidades modernas, crucialmente afetado pelas técnicas, modificara os costumes e a sensibilidade humanas, de sorte que o cinema, também fundamentado nos avanços tecnológicos, permite aos seus espectadores que vivenciem imagens também frenéticas e fragmentadas, em especial através da montagem, e por isso, exerça um papel terapêutico e didático aos seus espectadores, além de, através de desenhos animados e filmes

\footnotetext{
${ }^{1}$ Memória involuntária seria aquele tipo de memória que, inconscientemente, remete a experiências do passado, fazendo com que o sujeito tenha um acesso direto às suas lembranças de outrora, e que faz com que o momento presente seja permeado com esta atmosfera tida como mágica e prazerosa para o sujeito que a experimenta. A memória voluntária, por outro lado, seria aquela com que o sujeito tenta vivenciar propositalmente, buscando recursos no presente que possam remeter ao passado e fornecer as lembranças desejadas.
} 
burlescos, oferecer uma catarse das fantasias violentas e sadomasoquistas da população, que poderiam desembocar em atitudes agressivas ou em uma guerra.

\section{A arte pictórica e o cinema}

Para Benjamin, uma forma de arte alcança sua maturidade quando consegue atingir a intersecção de três linhas evolutivas: a primeira diz respeito ao modo como a técnica irá atuar sobre determinada forma de arte, ou seja, como os avanços da técnica irão determiná-la; a segunda é quando uma certa forma de arte tradicional procura suscitar efeitos em seus espectadores que irão ser obtidos mais facilmente por uma nova forma de arte advinda através da superação técnica; e a terceira remete às mudanças sociais nas estruturas de recepção que serão utilizadas e exploradas pelas novas formas de arte. Benjamin cita a relação entre o público de obras pictóricas e sua tentativa de contemplação coletivizada, já que tal tipo de apreciação se tornou decisiva a partir do advento do cinema (já que, no caso do cinema, tornase um absurdo uma sala vazia). Para o filósofo, esta relação demonstra um processo dialético no qual a função social de uma forma de arte é alterada a partir de sua relação e superação com a técnica, e conseqüentemente sobre os efeitos que ela produz, fazendo surgir novas formas de arte que irão absorver e recriar novas relações e efeitos entre a obra de arte e o público espectador.

No caso do cinema, para a realização de suas obras, é requerido todo um aparato tecnológico - constituído por refletores, câmeras, microfones, e demais aparelhagens - além de uma equipe técnica especializada e numerosa. Para o olhar de um observador comum, torna-se impossível acompanhar uma encenação executada em um estúdio, sem a interferência de todos esses equipamentos; a não ser, diz Benjamin, que o ponto de vista do observador pudesse coincidir com o da objetiva da câmera. Esta seria uma distinção crucial entre o cinema e o teatro, pois o teatro conheceria a perspectiva que preserva o caráter ilusionístico da cena, enquanto que no cinema, para Benjamin, sua natureza ilusionística seria resultado da montagem, e, portanto, de segunda ordem. Assim, “[...] no estúdio o aparelho impregna tão profundamente o real que o que aparece como realidade 'pura', sem o corpo estranho da máquina, é de fato o resultado de um procedimento puramente técnico [...]" (BENJAMIN, 1996, p. 186). De fato, a imagem é captada pela câmera sob um ângulo especial, que exclui os demais aparelhos (e por isso interfere na realidade), além de ser montada com outras imagens de procedimento semelhante; por isso, diz Benjamin, a imagem cinematográfica é, de fato, uma visão superficial da realidade, já que ela aparenta-se como depurada de qualquer intervenção técnica, enquanto é de fato esta intervenção que a produz. 
Benjamin prossegue sua investigação, expandindo sua comparação para a relação entre o cinema e a pintura. Para tal, faz uma analogia entre o cirurgião e o curandeiro mágico. Enquanto o primeiro intervém no corpo do doente, através de um instrumento, o segundo impõe suas mãos sobre o enfermo a uma certa distância. Assim, o cirurgião diminui ao máximo sua distância com o paciente, aumentando-a discretamente devido à sua cautela em manusear os instrumentos cirúrgicos; enquanto o curandeiro diminui apenas um pouco sua distância, ao estender as mãos, mas a aumenta bastante em virtude de sua autoridade.

\footnotetext{
O mágico e o cirurgião estão entre si como o pintor e o cinegrafista. O pintor observa em seu trabalho uma distância natural entre a realidade dada e ele próprio, ao passo que o cinegrafista penetra profundamente as vísceras dessa realidade. As imagens que cada um produz são, por isso, essencialmente diferentes. A imagem do pintor é total, a do operador é composta de inúmeros fragmentos, que se recompõem segundo novas leis (BENJAMIN, 1996, p. 187).
}

Desta forma, graças à capacidade que o cinema tem de penetrar, a partir de sua aparelhagem, no âmago da realidade, e, assim, proporcionar uma imagem livre de toda intervenção técnica, sua descrição (ou representação) da realidade é infinitamente mais significativa para o homem moderno do que a imagem pictórica; pois, o cinema passa a atender à necessidade que o homem tem de exigência da arte: a de oferecer um aspecto da realidade livre de toda intervenção do aparelho. Isto é alcançado pelo cinema, por mais paradoxal que isso possa parecer, já que o cinema, por sua vez, se funda em um aparelho técnico de reprodução.

A partir da análise da recepção das obras pictóricas, Benjamin expõe sua tese de que "A reprodutibilidade técnica da obra de arte modifica a relação da massa com a arte. Retrógrada diante de Picasso, ela se torna progressista diante de Chaplin" (BENJAMIN, 1996, p. 187). Assim, segundo a análise benjaminiana, a massa de espectadores mantém atitudes diferentes quando confrontadas com obras de pintores renomados que propõem experimentos estéticos (como Picasso), ou quando defronta obras audiovisuais que mesclam aspectos cômicos e mímicos (como é o caso dos filmes de Chaplin). Para Benjamin, o comportamento progressista é caracterizado pela junção entre o prazer de ver e sentir com a atitude de especialista. Para o filósofo, isto indica uma sinalização do valor social de uma forma de arte, pois, para ele, quanto menor a distância entre tais tipos de atitude - a de fruição e a de crítica - maior o significado social desta forma de arte. Assim, o cinema consegue unir direta e internamente estas duas posturas no espectador, apontando para uma forte significação social de sua arte; ao contrário do que ocorre em relação à pintura, que, segundo a análise benjaminiana, faz com que os espectadores desfrutem do novo sem criticá-lo, ou critiquem-no 
sem desfrutá-lo, ao contrário do que ocorreria no cinema - além de que, no cinema, sua forma de recepção passa a ser coletivizada.

O decisivo, aqui, é que no cinema, mais que em qualquer outra arte, as reações do indivíduo, cuja soma constitui a reação coletiva do público, são condicionadas, desde o início, pelo caráter coletivo dessa reação. Ao mesmo tempo que essas reações se manifestam, elas se controlam mutuamente (BENJAMIN, 1996, p. 188).

Assim, é como se os espectadores fossem massificados, ou passassem a ter suas reações impostas pela coletivização do público, de tal forma que as reações individuais são controladas entre si, ao mesmo tempo em que a coletividade constrange os indivíduos a exporem ou possuírem certas reações. Esta mudança de postura pode ser vista como uma modificação na relação entre o público e a obra de arte, de forma a implicar em uma refuncionalização social da mesma em relação ao seu modo de apreciação estética.

O ensaio A Obra de Arte na Época de sua Reprodutibilidade Técnica, notadamente, pode ser lido não só como a descrição do fim de uma idade estética, mas também como a tentativa de uma estética positiva da distração (Zerstreuung), portanto de um outro tipo de percepção (aisthêsis) que do recolhimento cultual e cultural, uma percepção ao mesmo tempo difusa e perspicaz que caracterizaria o grande público do cinema, segundo Benjamin (GAGNEBIN, 1989, p. 109-110 - grifos no original).

De fato, o cinema exige que sua recepção seja coletiva, como sempre foi o caso de outras formas de arte como a arquitetura, ou, na Antiguidade, a epopéia. Isto realmente modifica crucialmente a função social da obra de arte até então, pois as formas de arte tradicionais, ainda fundadas na valoração aurática de suas obras, ou seja, em sua unicidade, e na sensação de distanciamento entre os espectadores e as obras, fundamentam-se no ritual, ou seja, em uma recepção restrita ou até mesmo individualizada. Assim, no caso da pintura, a fruição passou a se distanciar da crítica, o que, para Benjamin, representa uma redução na significação social desta forma de arte, pois a recepção coletiva das obras pictóricas era mediada, e, mesmo após o advento das técnicas de reprodução, quando se tentou oferecer uma recepção coletiva para os quadros, o público ainda não pôde se organizar ou se controlar. Para Benjamin, no caso da exposição coletiva das pinturas, só havia uma forma de o espectador expressar o seu juízo: através do escândalo. Ou seja, “[...] a manifestação aberta do seu julgamento teria constituído um escândalo" (BENJAMIN, 1996, p. 188). Assim, Benjamin expõe sua difícil tese de que um mesmo público que tem uma reação progressista diante de um filme burlesco, teria uma reação retrógrada diante de um filme surrealista (ou seja, não conseguiria conciliar suas atitudes de crítica e de usufruto simultaneamente). "O público cinematográfico, de acordo com a avaliação de Benjamin, era capaz de unir o entretenimento à compreensão do sentido crítico dos bons filmes, quer dizer, era capaz de se distrair sem deixar de examinar aquilo que lhe estava proporcionando distração" (KONDER, 1999, p. 79). 
Apesar de esta ligação ser própria do cinema, Benjamin parece ressaltar que a massa de espectadores ainda não conseguia manter tal postura diante dos filmes que se propunham a experimentar nas formas semânticas da linguagem audiovisual, como é o caso dos filmes surrealistas.

\section{O inconsciente óptico}

Para Benjamin, uma das grandes funções sociais do cinema é mesmo a de oferecer um equilíbrio entre o homem e o aparelho. Tal tarefa seria realizada tanto pela forma como o homem representa a si mesmo diante do aparelho, como pelo modo como ele passa a representar o mundo através do mesmo. Através das imagens oferecidas pela objetiva da câmera, os espaços que nos cercam - aparentemente vulgares e rotineiros - passaram a ser vistos sob novas perspectivas. O plano geral e os movimentos de câmera proporcionaram uma investigação do mundo ao nosso redor e de nosso cotidiano, além de despertar características da realidade visível até então desconhecidas. Ao mesmo tempo em que expuseram os inúmeros condicionamentos que determinam nossa existência, ofereceram "[...] um grande e insuspeitado espaço de liberdade" (BENJAMIN, 1996, p. 189). Para Rochlitz (1992, p. 214), o caráter de reprodução do cinema oferece uma ampliação da percepção sensível que, por sua vez, exerce uma exigência ética de transformação, pois o espectador passa a ter o poder sobre a unicidade e o distanciamento entre ele e as imagens oferecidas pelas obras de arte.

Um dos aspectos revolucionários do cinema é o de conciliar o uso científico ao uso artístico das imagens, através de técnicas desconhecidas até então - tais quais a variação de velocidade da imagem (Benjamin enfatizava a câmera lenta, mas sabemos que a câmera acelerada também exerce papel semelhante), e a imagem ampliada - aspectos do mundo sensível, inimagináveis de serem enxergados até então, foram capazes de serem observados pelo homem. Assim, um novo mundo foi aberto à percepção humana, inalcançável a olho nu. "É evidente, pois, que a natureza que se dirige à câmara não é a mesma que a que se dirige ao olhar. A diferença está principalmente no fato de que o espaço em que o homem age conscientemente é substituído por outro em que sua ação é inconsciente" (BENJAMIN, 1996, p. 189). Assim, é como se fosse desvendado um inconsciente óptico, inacessível ao olho nu tal qual a psicanálise havia descoberto há pouco o inconsciente psicológico, pulsional. Este seria, portanto, um dos principais aspectos revolucionários do cinema, o de ampliar a percepção humana, e de conciliá-la com este novo mundo óptico desvelado. Para Benjamin, existem entre os dois tipos de inconsciente as relações mais estreitas. Mesmo que achemos natural o caminhar de alguém, ou tenhamos bastante familiaridade com o ato de segurar uma 
colher de metal com a mão, pouco sabemos acerca da fração de segundo exata em que uma pessoa dá um passo, ou qual a relação entre a pele e o objeto de metal (que, conjectura Benjamin, pode ser diferente de acordo com o momento ou estado de espírito de cada pessoa).

Para Benjamin a filmagem, abolindo a distância natural entre a realidade dada e aquele que a representa [...], penetra em profundidade na própria estrutura do real. [...] O cinema, enfocando os comportamentos mais cotidianos dos indivíduos, revela suas ações mais inconscientes. A fragmentação do mundo moderno exige mesmo esta apreensão através de instrumentos. É que o cinema, ampliando o mundo dos objetos com que tomamos contato, acarreta para Benjamin um aprofundamento da percepção e da experiência. O próprio processo técnico de produção da obra de arte conduz a esta metamorfose (PEIXOTO, 1982, p. 167-168).

Assim, as técnicas cinematográficas permitem conhecer o que se passa no íntimo de ações do dia-a-dia, aparentemente cotidianas e banais, mas que na verdade se mostram inconscientes, ou mesmo distorcidas. "Pois os múltiplos aspectos que o aparelho pode registrar da realidade situam-se em grande parte fora do espectro de uma percepção sensível normal" (BENJAMIN, 1996, p. 189-190 - grifo no original). Assim, a partir da ampliação da percepção sensível, e do desvelamento do inconsciente óptico, novas formas de comportamento - e, conseqüentemente de criação de valores e de costumes -, foram consolidadas, suscitando transformações na relação entre o público e a obra de arte, ou entre a massa e sua realidade social cotidiana. Segundo Rochlitz (1992, p. 177), para Benjamin, a imagem tem o poder de suscitar a ação, ou seja, a partir de sua concretude imediata, a imagem provoca a prática. Isto pode denunciar o poder de influência que o cinema possui sobre nossos pensamentos e, em última instância, sobre nossos comportamentos, ou, em outros termos, o poder de persuasão política oferecido pelo cinema. Com isso, chegamos a outro aspecto da tese benjaminiana que pode ser tomada como ousada e visionária: a de que o cinema passa a influenciar o inconsciente dos espectadores, através dos sonhos, alucinações e distúrbios psíquicos da população.

\footnotetext{
Muitas deformações e estereotipias, transformações e catástrofes que o mundo visual pode sofrer no filme afetam realmente esse mundo nas psicoses, alucinações e sonhos. Desse modo, os procedimentos da câmara correspondem aos procedimentos graças aos quais a percepção coletiva do público se apropria dos modos de percepção individual do psicótico ou do sonhador (BENJAMIN, 1996, p.190).
}

Além de sinalizar para uma idéia de inconsciente coletivo exercida pela arte - e em especial pelo cinema -, Benjamin questiona até que ponto o sonho pode ser encarado como uma atividade estritamente individual. Podemos questionar que pelo menos as influências e estímulos sensórios dos sonhos e pensamentos dos indivíduos passam a ser coletivizados pelo cinema, pois além de que sua recepção se dá de forma massificada, seu potencial de ilusionismo, ou forma de representação da realidade, é muito próxima daquela do mundo 
autêntico apreendida pela percepção sensível normal. Para Benjamin, é como se o cinema tivesse coletivizado o sonho, menos pela descrição do mundo onírico do que pela criação de personagens do imaginário coletivo, como o Mickey Mouse. Em Experiência e Pobreza, Benjamin irá considerar a criação deste personagem da Disney, como uma resposta dos homens à sua pobreza de experiências - ao dizer que os homens não passam a aspirar a novas experiências, mas apenas à possibilidade de ostentação de tal pobreza, como se daí fosse possível resultar algo de decente -, e que a desolação do proletariado após sua jornada de trabalho poderia ser recompensada pela liberação da imaginação.

\begin{abstract}
Ao cansaço segue-se o sonho, e não é raro que o sonho compense a tristeza e o desânimo do dia, realizando a existência inteiramente simples e absolutamente grandiosa que não pode ser realizada durante o dia, por falta de forças. A existência do comundongo Mickey é um desses sonhos do homem contemporâneo. É uma existência cheia de milagres, que não somente superam os milagres técnicos como zombam deles (BENJAMIN, 1996, p. 118).
\end{abstract}

Para Benjamin, a existência de Mickey se basta a si mesma, além de que, em seus desenhos, a natureza se concilia com a técnica, de forma que, em cada episódio - para as pessoas comprometidas e fatigadas com as inúmeras tribulações diárias, que não vêem perspectivas para suas vidas, a não ser como meios da linha de montagem - o sonho passa a superar e a transgredir as leis físicas e os próprios milagres técnicos, fomentando, assim, a ludicidade da população e o inconsciente coletivo da sociedade. Para Rochlitz (1992, p. 231), Benjamin concebe o inconsciente coletivo como vinculado às imagens dialéticas enquanto imagens de sonho, decifrando-as sob um duplo aspecto: o ideológico e o utópico. Assim, Benjamin pensaria que "[...] por meio do imaginário do qual nascem as imagens arcaicas do inconsciente coletivo, a projeção do futuro de uma sociedade é sempre tributária da origem" (ROCHLITZ, 1992, p. 232). Assim, ao recorrer ao inconsciente coletivo como portador de imagens remotas, Benjamin estaria tentando situar na sociedade a tensão entre os tempos, que permitiria a ação messiânica e surrealista a se manifestar no presente, como se o inconsciente coletivo permitisse ao sujeito crítico atualizar suas utopias que lhe tornam possível projetar-se no futuro.

Em seu ensaio sobre o cinema, Benjamin avalia que o predomínio da técnica pode gerar tensões nas massas que, em momentos críticos, podem ocasionar realmente no desenvolvimento de distúrbios alucinatórios (tais como as psicoses), que facilmente poderiam desencadear uma esquizofrenia em massa. No entanto, segundo Benjamin, esta mesma implementação técnica pode prover os espectadores do cinema de uma forma terapêutica contra tais distúrbios psíquicos, ao mesmo tempo em que amadurecem nossas relações com os 
recalques psicológicos e demais repressões que a civilização nos suscitou. "A hilaridade coletiva representa a eclosão precoce e saudável dessa psicose de massa" (BENJAMIN, 1996, p. 190). Segundo Benjamin, o cinema permite que, através de personagens e situações fictícias, possamos fazer vir à tona artificialmente nossas fantasias psíquicas - em especial as sadomasoquistas -, que agiriam como elementos terapêuticos contra tais pulsões destrutivas. De fato, o predomínio da técnica em nosso cotidiano, a partir da modernização da sociedade, reflete uma racionalização exacerbada que podou, ou restringiu através de traumas, muitas de nossas experiências, conduzindo nossa sociedade a um quadro de barbárie (ao qual Benjamin concebera como positiva, ao propor a recriação a partir da estaca zero); além de que as guerras mecanizadas modernas - e cada vez mais "cirúrgicas" - parecem nos fazer padecer, pelo menos nestes momentos críticos, sob uma verídica e fatídica barbárie civilizada.

No entanto, de acordo com a análise benjaminiana, esta mesma técnica, ao ser utilizada com fins estéticos, como no caso do cinema, oferece-nos uma terapia quanto a todos os tipos de transtornos psíquicos, além de nos oferecer um exercício para nossa percepção do mundo social que nos cerca, fragmentário e frenético. Assim, evidencia-se como a arte pode ter uma finalidade política, ou seja, pode permitir e ajudar a se criar valores, alterar comportamentos e modos de vivência e de pensamento. Para Rochlitz (1992, p. 280-281), o ensaio de Benjamin sobre a reprodutibilidade técnica de fato propõe que o cinema oferece uma terapia de cura das psicoses coletivas através do riso, além de prover os espectadores de um conhecimento que os permite se restabelecer em seu meio social; além de que proporia uma forma de comunicação pública da liquidação da aura, permitindo que o indivíduo se relacione com o mecanismo, ou seja, com o aparato tecnológico, através das obras cinematográficas.

Além do mais, a ampliação - e conseqüente modificação - da percepção sensível, gerada pelo cinema, passa a exercer um papel terapêutico para o atordoamento da população acarretado pela acelerada modernização de seu meio social e cotidiano, ou seja, pelo mundo afetado pela técnica. Tal papel se dá como uma espécie de exercício, no qual o filme irá proporcionar um modo de cura ou alívio para as tensões que a população adquiriu com o advento das técnicas em seu novo cotidiano, o que poderia gerar transtornos psicológicos e sociais. Assim, a arte moderna, e, em especial, o cinema, dá ao espectador a capacidade de adaptar sua percepção a este novo ambiente social, superando suas neuroses e possibilidades de desencadear psicoses ou mesmo alucinações aliadas à esquizofrenia. Segundo Hansen (1999), Benjamin localiza com exatidão a arte moderna - e, em especial, o cinema -, como 
uma investigação que exerce um treino, uma prática, para a inter-relação entre a natureza, a técnica (concebida como segunda natureza), e a humanidade.

O filme assume esta tarefa não simplesmente no sentido de uma adaptação behaviorista das percepções e reações humanas do regime do aparato [...], mas porque o filme tem o potencial de reverter, na forma de ação dramática, as consequiências catastróficas de uma ainda falha recepção da tecnologia (HANSEN). ${ }^{2}$

O cotidiano dos grandes centros urbanos foi freneticamente modificado pela ascensão das técnicas empregadas pela modernização da sociedade burguesa. Novos meios de comunicação e de transporte aceleraram e modificaram crucialmente a relação entre os homens entre si, e entre estes e o ambiente ao seu redor, além das relações comerciais; por isso, o cinema, como forma de arte fundada e cada vez mais aperfeiçoada pelas técnicas de reprodução, exerce um exercício terapêutico e pedagógico para a percepção humana e sua conseqüente relação com as tecnologias e seu cotidiano transformado pela implementação das mesmas.

\section{A superação da técnica pela arte}

Benjamin diz que os efeitos esperados por uma determinada forma de arte muitas vezes só são alcançados através de uma superação técnica da própria forma de arte; ou seja, pela consolidação de uma nova forma de arte fundada em tal superação. Assim, para Benjamin, uma das tarefas cruciais da arte é mesmo o de gerar uma procura por efeitos que só serão alcançados mais tarde. Desta forma, seria possível diagnosticar períodos críticos (ou mesmo de decadência), de certas formas de arte, a partir de seu estágio técnico, em paralelo ao de sua busca por efeitos estéticos. Seria possível avaliar a capacidade de uma forma de arte de prover resultados para sua demanda - ou perceber o estágio em que esta forma de arte não consegue mais atender a tal demanda de efeitos esperados -, de sorte que se poderia firmar uma nova forma de arte a partir de sua superação técnica, que irá passar a atender tal exigência de execução dos efeitos esperados.

Com a dita superação da pintura pela fotografia - pois, com o advento da fotografia, a forma de pintura mais difundida (o retrato), perdeu espaço, a ponto de os artistas e pensadores refletirem acerca da provável submissão da arte pictórica pela fotografia, ou mesmo sobre a possibilidade de seu desaparecimento completo -, as artes plásticas procuraram se superar, alterando sua própria estrutura, com a reinvenção de aspectos de sua linguagem artística própria. Assim, o dadaísmo - movimento de vanguarda artística do final da década de 10 do século XX - modificou a lógica de suas obras. Isto se deu pela

\footnotetext{
${ }^{2}$ Todas as traduções de textos estrangeiros foram realizadas pelo autor do presente trabalho.
} 
necessidade de abranger a uma nova demanda oriunda do advento das novas técnicas de reprodução mecânica. Assim, o dadaísmo propôs poesias que eram na verdade "salada de palavras" - ou seja, constituídas por termos dispostos aleatoriamente -, ou obras plásticas com elementos do cotidiano moderno (tais como bulas de remédio ou passagens de trem). Para Benjamin, sua maior intenção era a de produzir (tanto na literatura quanto na pintura), choques similares aos advindos do cinema; desta forma, seus partidários prezavam pela liquidação completa da aura. De fato, o dadaísmo propõe uma ruptura no fazer e apreciar artísticos através da quebra proposital da sintaxe da linguagem artística (seja ela pictórica ou literária, por exemplo). Além disso, suas obras são totalmente desprovidas de qualquer aura.

\begin{abstract}
Os dadaístas estavam menos interessados em assegurar a utilização mercantil de suas obras de arte que em torná-las impróprias para qualquer utilização contemplativa. Tentavam atingir esse objetivo, entre outros métodos, pela desvalorização sistemática do seu material [...] Com esses meios, aniquilavam impiedosamente a aura de suas criações, que eles estigmatizavam como reprodução, com os instrumentos da produção (BENJAMIN, 1996, p. 191).
\end{abstract}

Assim, o maior intuito destes artistas era mesmo o de provocar tanto o choque pela perda da aura, como o escândalo público - através de quebras sistemáticas e propositais da sintaxe da linguagem artística de suas obras. E embora construíssem suas obras a partir de meios de produção tradicionais, tachavam-nas de reproduções, caracterizando-as completamente como destituídas de aura. Com isso, passaram a questionar tanto a função social das obras de arte, quanto o valor das mesmas, além de impedirem uma apreciação tradicional, na qual se exigia uma contemplação (oriunda de uma concentração), que conduziria a uma associação de idéias. De fato, com o cinema, não mais seria possível acolher uma obra deste modo. O que parece que os dadaístas intentaram foi refletir esta modificação, expandindo-a para os campos da literatura e das artes plásticas.

Benjamin diz ser impossível doar algum tempo ao recolhimento ou à avaliação diante de tais obras. Inclusive, fazia parte do propósito dos dadaístas impedir a possibilidade de contemplação de suas obras. "Ao recolhimento [...], opõe-se a distração, como uma variedade do comportamento social" (BENJAMIN, 1996, p. 191 - grifos no original). As obras dadaístas de fato apenas permitiam uma distração intensa, e tinham por objetivo provocar o escândalo como forma de comportamento (que na verdade era tido como antisocial), suscitando a indignação pública. Esta era de fato a sua exigência; daí sua refrega com os valores tradicionais tanto artísticos, quanto morais ou políticos, apregoados pela burguesia. Realmente, este movimento artístico também continha em si conseqüências políticas, associando sua manifestação estética ao anarquismo, ou ao choque total - e conseqüente 
transgressão - de todos os valores vigentes, sistematicamente gerado através de escândalos públicos.

\begin{abstract}
A razão fundamental por que as criações dadaístas já não admitem a contemplação é seu caráter de choque [...] Através da violenta sacudida que a obra dadaísta produz no espectador, e que ele tem de assimilar de uma maneira ou de outra, a própria obra se desvia de si mesma, da coisa ou objeto que ela é. Ela distrai de sua aparição singular, e desvia para o que de início pareceria ser uma espécie de reflexão subjetiva [...] pelo sujeito, da perturbação violenta que sofreu (GASCHÉ, 1997, p. 205).
\end{abstract}

Com isso, a partir do dadaísmo, e com o cinema, o modo de apreciação artística não se sustenta mais no recolhimento destinado à contemplação, mas sim na distração (embora crítica) das massas, acarretada a partir dos choques audiovisuais provenientes da montagem. Isso alterava (realmente de forma escandalosa), o caráter de beleza e de harmonia apregoado pelas formas de arte tradicionais, passando a se constituir em um choque real de dupla feição, que não mais tinha a pretensão de enaltecer o espírito humano, mas inclusive o de espelhar sua desgraça e miséria. Por isso, os dadaístas associavam o choque moral ao choque físico, como se o segundo fosse conduzido pelo primeiro. Isto, segundo a análise benjaminiana, era realmente extraordinário, pois possibilitou o ressurgimento da qualidade tátil na recepção das obras, tão crucial para a arte em suas épocas de reconstrução.

O dadaísmo colocou de novo em circulação a fórmula básica da percepção onírica,
que descreve ao mesmo tempo o lado tátil da percepção artística: tudo o que é
percebido e tem caráter sensível é algo que nos atinge. Com isso, favoreceu a
demanda pelo cinema, cujo valor de distração é fundamentalmente de ordem tátil,
isto é, baseia-se na mudança de lugares e ângulos, que golpeiam intermitentemente o
espectador (BENJAMIN, 1996, p. 191-192 - grifo no original).

O cinema, por sua característica própria, fez uso, a um só tempo, do choque proveniente da montagem (que leva o público à distração), e o da perda da aura (que o mobiliza à crítica das formas de arte tradicionais). Por isso, Benjamin considerava que, nas obras progressistas, o cinema unificara em um nível mais alto os dois efeitos de choque tanto o físico quanto o moral - e, por isso, poderia ser encarado como uma superação técnica do dadaísmo, que ainda impulsionava o choque físico através do choque moral. Para Konder (1999, p. 79), a ampliação da percepção sensível ocasionada pelo cinema, encarado como uma superação da proposta dadaísta, poderia ser considerada como uma modificação na linguagem artística e conseqüentemente na linguagem humana, especialmente no que concerne ao movimento; por isso, esta nova forma de arte reconquistaria a criatividade inerente também à práxis, como movimento de transformação da realidade.

Segundo Gagnebin (1989, p. 117), Benjamin tinha uma certa aproximação com a obra de Brecht e sua proposta de distanciamento (ou estranhamento), como forma de se 
relacionar com o público, partindo de uma interrupção de pensamento provocada pela trama da peça do seu teatro ou pela própria inversão na identificação com o público e os personagens, como uma sugestão de liame entre a interrupção de pensamento, a crítica e a verdade. Assim, a violência da crítica filosófica ou da historiografia materialista revolucionária ou messiânica - vai sempre de encontro a uma idéia de beleza alicerçada na totalidade de uma ilusão mítica, de uma narração, ou da história ordinária. Por isso, para Gagnebin (1989, p. 119), a interrupção do pensamento - acarretada pelos choques advindos das manifestações estéticas tais como o dadaísmo ou o cinema - pode ser encarada como um gesto crítico e político. Para Peixoto (1982, p. 168-169), a experiência da interrupção pode reforçar a capacidade de apreensão da realidade, não implicando, portanto, em uma perda do significado do mundo, de forma que a diversão passa a ser uma nova forma de percepção e de reflexão. Ainda segundo Gagnebin, Benjamin considera paradoxal a lembrança da promessa messiânica aliada à exigência de transformação radical da realidade.

Um paradoxo que se esclarece, se se compreende que o verdadeiro objeto da
lembrança e da rememoração não é, simplesmente, a particularidade de um
acontecimento, mas aquilo que, nele, é criação específica, promessa do inaudito,
emergência do novo [...] A veemência, mesmo a violência da tradição profética e a
radicalidade da tradição marxista se encontram aqui na exigência de uma salvação
que não consista simplesmente na conservação do passado, mas que seja também
transformação ativa do presente (GAGNEBIN, 1989, p. 120-122).

Portanto, os choques estéticos (ocasionados pelo teatro épico ou pelo dadaísmo - e mais efetiva e eficientemente pelo cinema), tinham o papel político de fornecer uma nova interpretação crítica da realidade social, e conseqüentemente da história. Este choque ou paralisação pode ser encarado como revolucionário, pois tem a capacidade de conduzir o espectador a uma imagem dialética - ou seja, a uma cristalização dos tempos, na qual se torna possível encarar uma transformação do futuro através do confronto entre a rememoração messiânica do passado oprimido e o momento presente, que por isso se torna revolucionário. Esta paralisação era considerada crucial por Benjamin para o historiador materialista comprometido com a transformação da realidade social, e com a história de nossos antepassados mortos e subjugados; de forma que o artista, por sua vez, teria o papel de fazer vir à tona os sonhos remotos que não se concretizaram. Desta forma singular, Benjamin propunha conciliar o messianismo, típico da mística judaica, com a exigência marxista de transformação da realidade sócio-política.

Para Rochlitz, embora fizesse uma distinção entre a abordagem teórica de um artista e o conteúdo de sua obra - de forma que o pensamento teórico e a prática artística fossem considerados como incomunicáveis, ou mesmo inconsistentes entre si, no espírito de um 
mesmo autor -, a arte possuiria, segundo a análise benjaminiana, uma recepção anticonformista, pois esta teria o papel de romper com as visões hegemônicas transmitidas sob uma falsa continuidade das tradições. "O elemento destruidor, crítico, é [...] constitutivo de qualquer estudo de um objeto histórico [...], para evitar a influência da 'cultura' estabelecida, sempre suspeita de cumplicidade com as forças socialmente dominantes" (ROCHLITZ, 1992, p. 274). Assim, os choques estéticos das linguagens artísticas, e a catarse da destruição do elemento tradicional da arte (imposta pela dissolução da aura), poderiam fundamentar um papel político de questionamento e de contestação da ordem vigente em todos os domínios tanto históricos, sociais e políticos, quanto morais ou estéticos.

\section{A percepção das massas no cinema}

Ao comparar a pintura tradicional com o cinema, Benjamin explica de que modo a apreciação da obra de arte é alterada por sua nova forma de percepção. Pois a pintura “[...] convida o espectador à contemplação; diante dela, ele pode abandonar-se às suas associações. Diante do filme, isso não mais é possível [...] A associação de idéias do espectador é interrompida imediatamente, com a mudança de imagem" (BENJAMIN, 1996, p. 192). Para Benjamin, é neste fluxo (mesmo que descontínuo) de mudança de imagens provenientes da montagem que se baseia o choque no cinema, e que, enquanto choque, precisa ser retido por uma atenção aguçada pelo espectador. Com isso, vemos como o cinema se diferencia das formas de arte tradicionais no seu modo de apreciação (ou seja, na capacidade que o espectador possui de julgar a obra que acolhe), o que modifica a percepção sensível da obra de arte.

Peixoto irá dizer ainda que a contraposição benjaminiana entre pintura e cinema esclarece o novo comportamento do espectador diante das obras: "Um quadro nos convida à contemplação, leva as pessoas à associação de idéias. $\mathrm{O}$ filme, ao contrário, impede que o olho fixe uma imagem, a sua sucessão impede qualquer associação no espírito do espectador. Provoca portanto um desconcerto nele. É inebriante." (PEIXOTO, 1982, 169). A distração (tal qual exercitada pelo flâneur), oferece uma diversão adaptativa ao ambiente hostil da modernidade, remediando seus efeitos traumáticos. E, de fato, a tese benjaminiana correlaciona a maneira como o espectador recebe a obra de arte com o modo como ele reage aos estímulos de sua esfera social modificada pela técnica. "O cinema é a forma de arte correspondente aos perigos existenciais mais intensos com os quais se 
confronta o homem contemporâneo" (BENJAMIN, 1996, p. 192). Assim, segundo a tese benjaminiana, o conjunto de choques que o cinema produz no espectador exerce uma função terapêutica nos indivíduos da sociedade moderna, adaptando sua percepção aos choques oriundos das repentinas mudanças de espaço-tempo ocasionadas pela ascensão e implementação das técnicas no cotidiano das grandes cidades. $\mathrm{O}$ ambiente - dito hostil - da sociedade moderna fornece perigos (em especial, a guerra), para a integridade perceptiva e física dos cidadãos. Para Benjamin, as metamorfoses no aparelho perceptivo humano provenientes do cinema podem ser comparadas, em uma escala individual, às que os transeuntes sofrem em uma grande cidade, ou, em uma escala histórica, às daqueles que procuram combater a ordem social vigente. Peixoto (1982, p. 142) diz que, para Benjamin, a experiência de choque nas metrópoles corresponde à reflexão e a sensibilidade do homem moderno. Desta forma, a experiência - entendida como a capacidade de encadear acontecimentos, e não meramente fixá-los na memória parece querer se perder através dos choques provenientes do cotidiano moderno. A experiência de choque...

Vem subverter inteiramente a tradição, bloquear a ambientação dos indivíduos,
dissolver os vínculos ainda existentes entre as coisas e as pessoas. A indiferença, o
fechamento insensível de cada um nos seus interesses privados, o ritmo alucinado,
são insuportáveis a quem não os tivesse como seu elemento natural [...] Inúmeros
textos de Benjamin estão permeados por esta sensação da tensão urbana, da
violência latente, os crimes, os acidentes e a marginalização que se multiplicam na
grande cidade (PEIXOTO, 1982, p. 142).

Uma das teses de Benjamin é a de que o modo de vivência dos seres humanos é condicionado pela forma de percepção, enquanto esta última é marcadamente influenciada pelas artes. E, como Benjamin está a tratar dos avanços das técnicas na produção artística, o questionamento recai em como estes avanços modificam o modo de perceber e de existir dos seres humanos. Portanto, a arte determina o modo de percepção dos homens, e este, por sua vez, influencia na modificação de seus modos de vivência. Assim, é possível, para Benjamin, compreender o porquê das convulsões sociais de seu tempo, através do entendimento das transformações perceptivas geradas pela ascensão das técnicas de reprodução.

Segundo Benjamin, é a partir da massa de espectadores que surge uma nova atitude em relação à apreciação da obra de arte, pois é a partir do cinema que o público irá modificar sua forma de se relacionar com a arte. De fato, sua participação passa a ser coletiva. Portanto, há uma diferença drástica em como a massa se posiciona e se comporta diante de um filme, e como um crítico de arte se porta diante de uma obra de arte (mesmo que esta seja 
cinematográfica). "Afirma-se que as massas procuram na obra de arte distração, enquanto o conhecedor a aborda com recolhimento. Para as massas, a obra de arte seria objeto de diversão, e para o conhecedor, objeto de devoção" (BENJAMIN, 1996, p. 192 - grifos no original). Vemos que aquele que tem conhecimento das regras estéticas e dos demais funcionamentos da arte cinematográfica irá se portar, diante dela, ainda com recolhimento, na tentativa de contemplá-la e entendê-la; enquanto que a massa, por sua vez, procura apenas se distrair (e se divertir), levada pelos choques audiovisuais provenientes da montagem.

Benjamin diz que a distração e o recolhimento se contrastam, pois enquanto neste a obra permite que os pensamentos do espectador se associem livremente - de acordo com o conteúdo da obra, como se o espectador mergulhasse e se dissolvesse nela -, o espectador distraído tem seus pensamentos condicionados pela obra, de forma que ele a absorve em seu fluxo, fazendo-a, portanto, mergulhar diante de si. Para Carla Milani Damião (2007), enquanto no recolhimento há uma imersão, uma interiorização da obra (embora não implique em sua posse), na atitude distraída há um relaxamento físico, uma atenção distencionada (típica do trabalho manual), diferentemente da atenção tencionada da contemplação. Benjamin diz que a arquitetura é a forma de arte com a história mais longa da humanidade, já que a necessidade de morar é perpétua. Portanto, para ele, “[...] é importante ter presente a sua influência [da arquitetura] em qualquer tentativa de compreender a relação histórica entre as massas e a obra de arte" (BENJAMIN, 1996, p. 193). Assim, ao analisar a forma de recepção do cinema, Benjamin faz um paralelo com a arquitetura, na qual as obras de arte são coletivizadas e sentidas por aqueles que entram nelas, e, portanto, as usam; enquanto são vistas por aqueles que a contemplam, tal qual o viajante diante de prédios famosos, que ainda busca o recolhimento.

Benjamin explicita, portanto, dois conceitos de percepção sensível que irão condicionar a recepção das obras de arte: a tátil, ou seja, sensitiva (percebida pelos sentidos como um todo), e a óptica (apreendida pela visão). E compara as duas formas de apreciação artística com estas formas de recepção, "Pois não existe nada na recepção tátil que corresponda ao que a contemplação representa na recepção ótica. A recepção tátil se efetua menos pela atenção que pelo hábito" (BENJAMIN, 1996, p. 193). Desta forma, enquanto a contemplação está associada à percepção óptica, a percepção tátil associa-se à atitude distraída da massa, de forma que a obra passa a conduzir seus pensamentos e afetar suas percepções como um todo. "O mundo é acessível mais pela diversão do que pela concentração. A teoria do 'flânerie' em Benjamin postula o divertimento como princípio do 
conhecimento e do comportamento social" (PEIXOTO, 1982, p. 146 - grifos no original). Vemos que, para Peixoto, a diversão passa a ser uma forma tanto de comportamento, quanto de apreensão da realidade.

Benjamin diz que a recepção tátil se dá pelo hábito, que conduz à distração, enquanto que a recepção visual ocorre a partir do recolhimento do espectador. Gagnebin diz (2007) que o habitar se dá pelo hábito - como conceitos correlacionados -, que leva a uma tatibilidade na arquitetura, de forma que os habitantes devem usar os prédios, e, para isso, esquecê-los, diferentemente dos turistas que irão contemplá-los. Benjamin diz que esta nova forma de recepção da obra de arte - a tátil - modifica nossa percepção sensível, abrindo-a para novas possibilidades. Para Benjamin, apenas a contemplação - fundamentada pela recepção óptica é insuficiente para "[...] superar tarefas impostas ao aparelho perceptivo do homem, em momentos históricos decisivos [...] Elas se tornam realizáveis gradualmente, pela recepção tátil, através do hábito" (BENJAMIN, 1996, p. 193). Mas Benjamin diz ainda que o espectador distraído também pode habituar-se, e a prova disso seria sua capacidade de realizar tarefas enquanto está distraído. Segundo Peixoto, Benjamin irá recusar a idéia de que a massa procura apenas diversão enquanto a arte exigiria concentração, de forma que o choque deixa de ser um problema moral, e passa a ser um elemento para se entender o cinema.

Pois aqui a oposição entre dispersão e concentração remete a dois modos distintos de percepção, em que se pode penetrar na obra ou deixar que ela penetre em nós. A acolhida pode portanto ser tátil, sensível, ou visual, contemplativa [...] Mesmo aquele que se diverte pode assimilar hábitos [...] O costume é aliás condição para que se realizem tarefas cotidianas na dispersão (PEIXOTO, 1982, p. 171).

Portanto, também o hábito modifica o modo de percepção, e conseqüentemente o de recepção da obra de arte, o que afeta sua apreciação. No caso da apreciação distraída, a recepção adequada é a tátil - já que ela afeta os sentidos como um todo -, que deve ser, por sua vez, automatizada pelo hábito, já que o espectador deve ser capaz de absorver e interpretar os choques audiovisuais provenientes da montagem com uma atenção ao mesmo tempo espontânea e direcionada para as imagens; ou seja, mesmo que habitualmente distraída, a atenção do espectador é apurada o bastante. Damião (2007) corrobora a idéia de que no dadaísmo o choque ainda era moral, enquanto no cinema este passa a ser físico; para ela, a recepção dos choques corresponde ao recebimento da experiência moderna.

Segundo Gasché, a oposição entre distração e concentração poderia ser usada para apartar a alta cultura da - assim chamada - "baixa cultura”, pois, nesta segunda, a disposição de espírito das massas seria caracterizada “[...] pela desatenção, pelos modos de pensar rotineiros e por uma relação difusa, aleatória, com seu meio ambiente" (GASCHÉ, 1997, p. 
208); mas, enquanto alguns teóricos - mesmo que membros da Escola de Frankfurt, como Adorno - pudessem usar este argumento para desqualificar a cultura de massa, ou, em especial, o cinema enquanto arte, para Benjamin, segundo Gasché, são exatamente estas características desprezadas de como a massa absorve o choque da perda da aura que devem ser exaltadas como disposições de espírito. No entanto, Benjamin investiga como a distração pode ser adquirida pelo hábito, pois, segundo Gasché (1997, 209), o sujeito se torna autônomo, embora distraído, ou seja, embora sua autoridade individual seja despojada em um sentido de o sujeito se tornar massificado, a partir da atitude de apreciação distraída o espectador poderá ter uma maior autonomia de pensamento (diferentemente da associação de idéias conferida pelo recolhimento); além disso, Benjamin aprova a reação do público massificado aos efeitos de choque do cinema.

Na verdade, esse feito crítico não é alcançado apenas num estado de distração, mas
também por hábito [...] Esse crítico distraído - que não dá nenhuma atenção direta
ao filme como objeto de arte, que, de passagem, amortece os choques que recebe
através de um nível mais elevado de presença de espírito e modos habituais de lidar
com eles, modos que foram ensaiados e praticados com outros membros da massa
diante da tela de cinema - é um crítico que conseguiu se livrar do feitiço da aura, e
de seu objeto [...] Esse crítico distraído é o primeiro cidadão de um mundo sem
magia (GASCHÉ, 1997, p. 209-210).

Para Benjamin, o que importa é avaliar como nossa percepção está apta para dar respostas a novas tarefas; e, como a distração (tal como proporcionada pela arte), pode contribuir para tal exercício de avaliação - terapêutico e pedagógico. E, como as pessoas, segundo Benjamin, tendem a evitar tais tarefas, o cinema tem suma importância para esta empreitada, já que esta forma de arte tem o poder de mobilizar as massas e de provê-las de uma nova forma de sensibilidade e de recepção da arte, ao mesmo tempo crítica e distraída.

A recepção através da distração, que se observa crescentemente em todos os domínios da arte e constitui o sintoma de transformações profundas nas estruturas perceptivas, tem no cinema o seu cenário privilegiado. E aqui, onde a coletividade procura distração, não falta de modo algum a dominante tátil, que rege a estruturação do sistema perceptivo (BENJAMIN, 1996, p. 194 - grifos no original).

Assim, a distração pode ser encarada como uma forma de transformação da percepção, pois a forma de apreciação buscada pela massa, a distraída, é motivada pela recepção tátil, e, já que esta forma de recepção afeta a percepção - ou seja, se dê pelos sentidos como um todo, modificando-os -, ela modifica a sensibilidade do espectador, principalmente devido ao fato de que o cinema faz com que a postura distraída se dê a partir da visão (devido aos choques visuais provenientes da montagem). Esta característica gera uma grande tensão na relação entre estas duas formas de recepção e de apreciação, já que a forma de apreciação normalmente ligada à recepção óptica é a contemplativa, enquanto a recepção 
tátil se dá pelo hábito, e está relacionada com a distração. No entanto, no cinema, a apreciação é distraída, e, portanto, adquirida pela recepção tátil, embora seus estímulos partam da visão. Assim, esta nova forma de arte integra as duas formas de recepção - tátil e óptica - em uma só vertente; e, embora conduza a massa de espectadores à distração (diferentemente de no caso do conhecedor, que ainda irá procurar contemplá-la através do recolhimento), o cinema permite que ela desenvolva a crítica no seu processo de apreciação artística - distraída proporcionada pela recepção tátil habituada. Devido a todas essas características, Benjamin atribui ao cinema uma grande importância para a estética filosófica.

\section{Referências}

BENJAMIN, Walter. Obras escolhidas. Trad. Sergio Paulo Rouanet. 10. reimpr. São Paulo: Brasiliense, 1996. v. 1: magia e técnica, arte e política

DAMIÃO, Carla Milani. Distração, tatibilidade e hábito: percepção e recepção no cinema segundo Walter Benjamin. In: COLÓQUIO WALTER BENJAMIN, 2007, Salvador. Apresentação oral.

GAGNEBIN, Jeanne Marie. História e narração em Walter Benjamin. São Paulo: Perspectiva, 1989.

GASCHÉ, Rodolf. Digressões objetivas: sobre alguns temas kantianos em "a obra de arte na era de sua reprodutibilidade técnica" de Benjamin. In: BENJAMIN, Andrew; OSBORNE, Peter. (Orgs). A filosofia de Walter Benjamin: destruição e experiência. Trad. Maria Luiza X. de A. Borges. Rio de Janeiro: Jorge Zahar, 1997. p. 193 - 214.

HANSEN, Miriam Bratu. Benjamin and cinema: not a one-way street. Critical Inquiry, Chicago, v. 25, n. 2, p. 306-343, winter 1999.

KONDER, Leandro. Walter Benjamin. o marxismo da melancolia. Rio de Janeiro: Civilização Brasileira, 1999.

PEIXOTO, Nelson Brissac. A sedução da barbárie: o marxismo da modernidade. São Paulo: Brasiliense, 1982.

ROCHLITZ, Rainer. O desencantamento da arte: a filosofia de Walter Benjamin. Trad. Maria Elena Ortiz Assumpção. Bauru: Edusc, 1992. 